\title{
Rainfall probability analysis for crop planning in Sambalpur district of Odisha, India
}

\begin{abstract}
This study was under taken in the U.G. thesis work in the Dept. Of SWCE, CAET, OUAT, Bhubaneswar during the year 2018-19. Sambalpur district has a geographical area of 6702 sq.km. Sambalpur district has latitude of $21^{\circ} 28^{\prime} 5.4660^{\prime \prime} \mathrm{N}$ and longitude of $83^{\circ}$ $58^{\prime} 31.4508^{\prime \prime}$ E. The average rainfall at Sambalpur district is around $1377.9 \mathrm{~mm}$, though it receives high amount rainfall but most of the rainfall occurred during kharif. So most of the crops get low yield due to improper crop planning. Thus, this study is proposed to be undertaken with the following objective: Probability analysis of annual, seasonal and monthly rainfall data of Sambalpur district. So rainfall data were collected from OUAT, Agril Meteorology Dept. from 2001 to 2017(17 years) monthly, seasonal and annual rainfall were analyzed .Probability analysis have been made and equations were fitted to different distributions and best fitted equations were tested. Monthly, Annual and seasonal probability analysis of rainfall data shows the probability rainfall distribution of Sambalpur district in different months, years and seasons. It is observed that rainfall during June to Sep is slightly less than $1000 \mathrm{~mm}$ and cropping pattern like paddy(110 days) may be followed by mustard is suitable to this region. Also if the kharif rain can be harvested and it can be reused for another rabi crop by using sprinkler or drip irrigation, which will give benefit to the farmers. Annual rainfall of Sambalpur district is $1377.9 \mathrm{~mm}$ at $50 \%$ probability level.
\end{abstract}

Volume 8 Issue $6-2019$

\author{
Dr. C.R.Subudhi,' Nibedita Jena, ${ }^{2}$ Sukanya \\ Suryavanshi, ${ }^{2}$ R.Subudhi' \\ 'Professor, CAET, OUAT, India \\ 2Ex. student, CAET, OUAT, India
}

Correspondence: Rajendra Subudhi, Professor, CAET, OUAT Bhubaneswar-751003, Odisha, Email rsubudhi5906@gmail.com

Received: November 14, 2019 | Published: December 26, 2019

Keywords: rainfall, probability analysis, crop planning

Sambalpur district has a geographical area of 6702 sq.km. Sambalpur district has latitude of $21^{\circ} 28^{\prime} 5.4660^{\prime \prime} \mathrm{N}$ and longitude of $83^{\circ} 58^{\prime}$ $31.4508^{\prime}$ E. The average rainfall at Sambalpur district is $1377.9 \mathrm{~mm}$, most of the rainfall occurred during kharif. Thus, this study is proposed to be undertaken with the following objective: Probability analysis of annual, seasonal and monthly rainfall data of Sambalpur district.

Thom $^{l}$ employed mixed gamma probability distribution for describing skewed rainfall data and employed approximate solution to non-linear equations obtained by differentiating log likelihood function with respect to the parameters of the distribution. Subsequently, this methodology along with variance ratio test as a goodness- of-fit has been widely employed Kar et al., ${ }^{2}$ Jat et al., ${ }^{3}$ Senapati et al., ${ }^{4}$ and Subudhi et al., ${ }^{5}$ applied incomplete gamma probability distribution for rainfall analysis. In addition to gamma probability distribution, other two-parameter probability distributions (normal, log-normal, Weibull, smallest and largest extreme value), and three-parameter probability distributions (log-normal, gamma, log-logistic and Weibull) have been widely used for studying flood frequency, drought analysis and rainfall probability analysis.

Gumbel $^{6}$ Chow., ${ }^{7}$ have applied gamma distribution with two and three parameter, Pearson type-III, extreme value, binomial and Poisson distribution to hydrological data.

Sachan S et al., ${ }^{8}$ attempted probability analysis using the rainfall data of 30 years(1976-2005) in various influencing raingauge stations viz., Damoh, Hatta, Jabera, and Deori falling in Bearma basin of Bundelkhand region, Madhyapradesh.

Gumbel, ${ }^{6}$ Hershfield \& Kohlar. ${ }^{9}$ have applied gamma distribution with two and three parameter, Pearson type-III, extreme value, binomial and Poisson distribution to hydrological data.

\section{Materials and methods}

The data were collected from District Collector's Office, Gajapati district for this study. Rainfall data for17 years from 2001 to 2017 are collected for the present study to make rainfall forecasting using different methods.

\section{Probability distribution functions}

For seasonal rainfall analysis of Gajapati district, three seasonskharif (June-September), rabi (October to January) and summer (February to May) are considered.

The data is fed into the Excel spreadsheet, where it is arranged in a chronological order and the Weibull plotting position formula is then applied. The Weibull plotting position formula is given by

$$
p=\frac{m}{N+1}
$$

where $m=$ rank number

$N=$ number of years

The recurrence interval is given by

$$
T=\frac{1}{p}=\frac{N+1}{m}
$$

The values are then subjected to various probability distribution functions namely- normal, log-normal (2-parameter), log-normal (3-parameter), gamma, generalized extreme value, Weibull, generalized Pareto distribution, Pearson, log-Pearson type-III and Gumbel distribution. Some of the probability distribution functions are described as follows: 


\section{Normal distribution}

The probability density is

$$
p(x)=(1 / \sigma \sqrt{2 \pi}) e^{-(x-\mu)^{2} / 2 \sigma^{2}}
$$

where $x$ is the variate, $\mu$ is the mean value of variate and $\sigma$ is the standard deviation. In this distribution, the mean, mode and median are the same. The cumulative probability of a value being equal to or less than $x$ is

$$
p(x \leq)=1 / \sigma \sqrt{2 \pi} \int_{-\infty}^{x} e^{-(x-\mu)^{2} / 2 \sigma^{2}} d x
$$

This represents the area under the curve between $-\infty$ and $x$.

\section{Log-normal (2-parameter) distribution}

The probability density is

$$
p(x)=\left(1 / \sigma_{y} e^{y} \sqrt{2 \pi}\right) e^{-\left(y-\mu_{y}\right)^{2} / 2 \sigma_{y}}
$$

where $y=\ln x$, where $x$ is the variate, $\mu_{y}$ is the mean of $y$ and $\sigma_{y}$ is the standard deviation of $y$.

\section{Log-normal (3-parameter) distribution}

A random variable $X$ is said to have three-parameter log-normal probability distribution if its probability density function (pdf) is given by:

$f(x)=\left\{\frac{1}{(x-\lambda) \sigma \sqrt{2 \pi}} \exp \left\{-\frac{1}{2}\left(\frac{\log (x-\lambda)-\mu}{\sigma}\right)^{2}\right\}, \lambda\langle x\langle\infty, \mu\rangle 0, \sigma\rangle 0\right\}$

where $\mu, \sigma$ and $\lambda$ are known as location, scale and threshold parameters, respectively.

\section{Pearson distribution}

The general and basic equation to define the probability density of a Pearson distribution

$$
p(x)=e \int_{-\infty}^{x} \frac{a+x}{b_{0}+b_{1} x+b_{2} x^{2}} d x
$$

where $a, b_{0}, b_{1}$ and $b_{2}$ are constants.

The criteria for determining types of distribution are $\beta_{1}, \beta_{2}$ and $k$ where

$$
\begin{gathered}
\beta_{1}=\frac{\mu_{3}^{2}}{\mu_{2}^{3}} \\
\beta_{2}=\frac{\mu_{4}}{\mu_{2}^{2}} \\
k=\frac{\beta_{1}\left(\beta_{2}+3\right)^{2}}{4\left(4 \beta_{2}-3 \beta_{1}\right)\left(2 \beta_{2}-3 \beta_{1}-6\right)}
\end{gathered}
$$

Where $\mu_{2}, \mu_{3}$ and $\mu_{4}$ are second, third and fourth moments about the mean.

\section{Log-Pearson type III distribution}

In this the variate is first transformed into logarithmic form (base 10 ) and the transformed data is then analyzed. If $X$ is the variate of a random hydrologic series, then the series of $Z$ variates where

$$
z=\log x
$$

are first obtained. For this z series, for any recurrence interval $T$ and the coefficient of skew $C_{s}$,

$$
\begin{aligned}
& \sigma_{z}=\text { standard deviation of the } Z \text { variate sample } \\
& =\sqrt{\sum(z-\bar{z})^{2} /(N-1)}
\end{aligned}
$$

And $C_{s}=$ coefficient of skew of variate $Z$

$$
=\frac{N \sum(z-\bar{z})^{3}}{(N-1)(N-2) \sigma_{z}^{3}}
$$

$\bar{z}=$ mean of $z$ values

$N=$ sample size $=$ number of years of record

\section{Generalized pareto distribution}

The family of generalized Pareto distributions (GPD) has three parameters $\mu, \sigma$ and $\xi$.

The cumulative distribution function is

$$
F_{(\varepsilon, \mu, \sigma)}(x)=\left\{\begin{array}{c}
1-\left(1+\frac{\xi(x-\mu)}{\sigma}\right)^{\frac{-1}{\xi}} \text { for } \xi \neq 0 \\
1-\exp \left(-\frac{x-\mu}{\sigma}\right) \text { for } \xi=0
\end{array}\right\}
$$

for $x \geq \mu$ when $\xi \geq 0$ and $\quad x \leq \mu-\frac{\sigma}{\xi}$ when $\quad \xi<0$, where $\mu \in \mathbb{R}$ is the location parameter, $\sigma>0$ the scale parameter and $\xi \in \mathbb{R}$ the shape parameter.

The probability density function is

$$
f_{(\xi, \mu, \sigma)}(x)=\frac{1}{\sigma}\left(1+\frac{\xi(x-\mu)}{\sigma}\right)^{\left(-\frac{1}{\xi}-1\right)}
$$

Or

$$
f_{(\xi, \mu, \sigma)}(x)=\frac{\sigma^{\frac{1}{\xi}}}{(\sigma+\xi(x-\mu))^{\left(\frac{1}{\xi}+1\right)}}
$$

again, for $x \geq \mu$, and $x \leq \mu-\frac{\sigma}{\xi}$ when $\xi<0$

\section{Generalized extreme value distribution}

Generalized extreme value distribution has cumulative distribution function 


$$
F(x ; \mu, \sigma, \xi)=\frac{1}{\sigma}\left[1+\xi\left(\frac{x-\mu}{\sigma}\right)\right]^{\left(-\frac{1}{\xi}-1\right)} \exp \left\{-\left[1+\xi\left(\frac{x-\mu}{\sigma}\right)^{\frac{-1}{\xi}}\right]\right\}
$$

For $1+\xi(x-\mu) / \sigma>0$, where $\mu \in \mathbb{R}$ is the location parameter, $\sigma>0$ the scale parameter and $\xi \in \mathbb{R}$ the shape parameter. The density function is, consequently

$$
f(x ; \mu, \sigma, \xi)=\frac{1}{\sigma}\left[1+\xi\left(\frac{x-\mu}{\sigma}\right)\right]^{\left(-\frac{1}{\xi}-1\right)} \exp \left\{-\left[1+\xi\left(\frac{x-\mu}{\sigma}\right)^{\frac{-1}{\xi}}\right]\right\}
$$

again, for $1+\xi(x-\mu) / \sigma>0$

\section{Gumbel's method}

The extreme value distribution was introduced by Gumbel (1941) and is commonly known as Gumbel's distribution. It is one of the most widely used probability-distribution functions for extreme values in hydrologic and meteorological studies. According to this theory of extreme events, the probability of occurrence of an event equal to or larger than a value $x_{0}$ is

$$
P\left(X \geq x_{0}\right)=1-e^{-e^{-y}}
$$

in which $y$ is a dimensionless variable and is given by

$$
\begin{gathered}
y=\alpha(x-a) \\
a=\bar{x}-0.45005 \sigma_{x}
\end{gathered}
$$

Thus $\quad y=\frac{1.2825(x-\bar{x})}{\sigma_{x}}+0.577 \ldots \ldots .$. where $\bar{x}=$ mean and $\sigma_{x}=$ standard deviation of the variate $X$. In practice it is the value of $X$ for a given $P$ that is required and such Eq. (i) is transposed as

$$
y_{p}=-\ln [-\ln (1-P)]
$$

Noting that the return period $T=1 / P$ and designating $y_{T}=$ the value of $y$, commonly called the reduced variate, for a given $T$

$$
y_{T}=-\left[\ln \ln \frac{T}{T-1}\right]
$$

$$
\text { Or } \quad y_{T}=-\left[0.834+2.303 \log \log \frac{T}{T-1}\right]
$$

Now rearranging Eq. (i), the value of the variate $\mathrm{X}$ with a return period $T$ is

$$
x_{T}=\bar{x}+K \sigma_{x}
$$

where

$$
K=\frac{\left(y_{T}-0.577\right)}{1.2825}
$$

\begin{tabular}{|c|c|c|c|c|c|c|c|}
\hline \multirow{2}{*}{ Months } & \multirow{2}{*}{ Best-fit Distribution } & \multirow{2}{*}{ RMSE Value } & \multicolumn{5}{|c|}{ Rainfall at probability levels } \\
\hline & & & $90 \%$ & $75 \%$ & $50 \%$ & $25 \%$ & $10 \%$ \\
\hline January & EV type III & 0.06126 & - & - & 2.17 & 17.48 & 34.45 \\
\hline February & Log Pearson & 0.03782 & - & - & 3.35 & 14.19 & 40.33 \\
\hline March & GEV & 0.0752 & - & - & - & 11.46 & 26.87 \\
\hline April & Pareto & 0.05627 & - & - & 4.76 & 19.85 & 36.06 \\
\hline May & Log Pearson & 0.03945 & - & 4.68 & 12.99 & 28.42 & 55.89 \\
\hline June & Pareto & 0.04644 & 77.20 & 107.93 & 170.47 & 261.13 & 355.21 \\
\hline July & Log Pearson & 0.04237 & 289.08 & 347.71 & 420.13 & 499.62 & 576.5 \\
\hline August & Weibull & 0.08646 & 199.83 & 298.53 & 424.23 & 559.63 & 685.42 \\
\hline September & Weibull & 0.05028 & 67.40 & 124.84 & 214.14 & 327.67 & 447.36 \\
\hline October & Exponential & 0.07427 & 3.58 & 18.17 & 50.64 & 106.13 & 179.5 \\
\hline November & Gamma & & - & - & - & 1.93 & 29.18 \\
\hline December & Pearson & 0.08093 & - & - & - & 12.59 & 39.38 \\
\hline
\end{tabular}

The above equations constitute the basic Gumbel's equations and are applicable to an infinite sample size ${ }^{10-16}$ (i.e. $N \rightarrow \infty$ ).

\section{Result and discussion}

The various parameters like mean, standard deviation, RMSE value were obtained and noted for different distributions. The rainfall at $90 \%, 75 \%, 50 \%, 25 \%$ and $10 \%$ probability levels are determined. The distribution "best" fitted to the data is noted down in a tabulated form in Table 1.

Table I Rainfall analysis of Sambalpur Block at different probability levels for different months and seasons 
Table Continued...

\begin{tabular}{|c|c|c|c|c|c|c|c|}
\hline \multirow{2}{*}{ Months } & \multirow{2}{*}{ Best-fit Distribution } & \multirow{2}{*}{ RMSE Value } & \multicolumn{5}{|c|}{ Rainfall at probability levels } \\
\hline & & & $90 \%$ & $75 \%$ & $50 \%$ & $25 \%$ & $10 \%$ \\
\hline Annual & Pareto & 0.0609 & 1121.05 & 1204.49 & 1377.9 & 1638.9 & 1925.39 \\
\hline $\begin{array}{l}\text { Kharif } \\
\text { (June-Sept) }\end{array}$ & EV type III & 0.07416 & 975.43 & 1083.18 & 1250.4 & 1462.76 & 1686.40 \\
\hline $\begin{array}{l}\text { Rabi } \\
\text { (Oct-Jan) }\end{array}$ & Exponential & 0.05306 & 11.04 & 30.15 & 72.7 & $|45.3|$ & 241.36 \\
\hline $\begin{array}{l}\text { Summer } \\
\text { (Feb-May) }\end{array}$ & Log Pearson & 0.03216 & 12.36 & 30.69 & 54.7 & 81.36 & 104.64 \\
\hline
\end{tabular}

In the present study, the parameters of distribution for the different distributions have been estimated by FLOOD frequency analysis software. The rainfall data is the input to the software programme. The best fitted distribution of different month and seasons and annual were presented in Table 1.The annual rainfall in 50\% probability was found to be $1377.9 \mathrm{~mm}$ for Sambalpur block of Odisha. During Kharif at $50 \%$ probability level, the rainfall is $1250.4 \mathrm{~mm}$ where as only 72.7 $\mathrm{mm}$ and $54.7 \mathrm{~mm}$ was received during rabi and summer respectively.

In the present study, the parameters of distribution for the different distributions have been estimated by FLOOD-flood frequency analysis software. The rainfall data is the input to the software programme. The best fitted distribution of different month and season and annual were presented in Table 6 . The annual rainfall in $50 \%$ probability was found to be $1377.9 \mathrm{~mm}$ for Sambalpur district of Odisha. During Kharif at $50 \%$ probability level, the rainfall is $1250.4 \mathrm{~mm}$ where as only 72.7 $\mathrm{mm}$ and $54.7 \mathrm{~mm}$ was received during rabi and summer respectively.

In the present study, the parameters of distribution for the different distributions have been estimated by FLOOD-flood frequency analysis software. The rainfall data is the input to the software programme. The best fitted distribution of different month and season and annual were presented in Table 1 . The annual rainfall in $50 \%$ probability was found to be $1377.9 \mathrm{~mm}$ for Sambalpur district of Odisha. During Kharif at $50 \%$ probability level, the rainfall is $1250.4 \mathrm{~mm}$ where as only 72.7 $\mathrm{mm}$ and $54.7 \mathrm{~mm}$ was received during rabi and summer respectively, so water harvesting structures may be made to grow crops during rabi and summer to utilize the water from the water harvesting structures to increase the cropping intensity of the area. It is also observed that at $75 \%$ probability level the June, July, Aug and Sept received more than $100 \mathrm{~mm}$, so farmers of these area can grow crops in upland areas suitably paddy can be grown followed by any rabi crop in rabi season like mustard or kulthi in upland areas. In Figure 1 the plot between different months and amount of rainfall in different probabilities were shown, It is observed that September month gets highest amount of rainfall compared to other months. Figure 2 shows the different cropping pattern in Sambalpur district as per the rainfall available in different weeks.

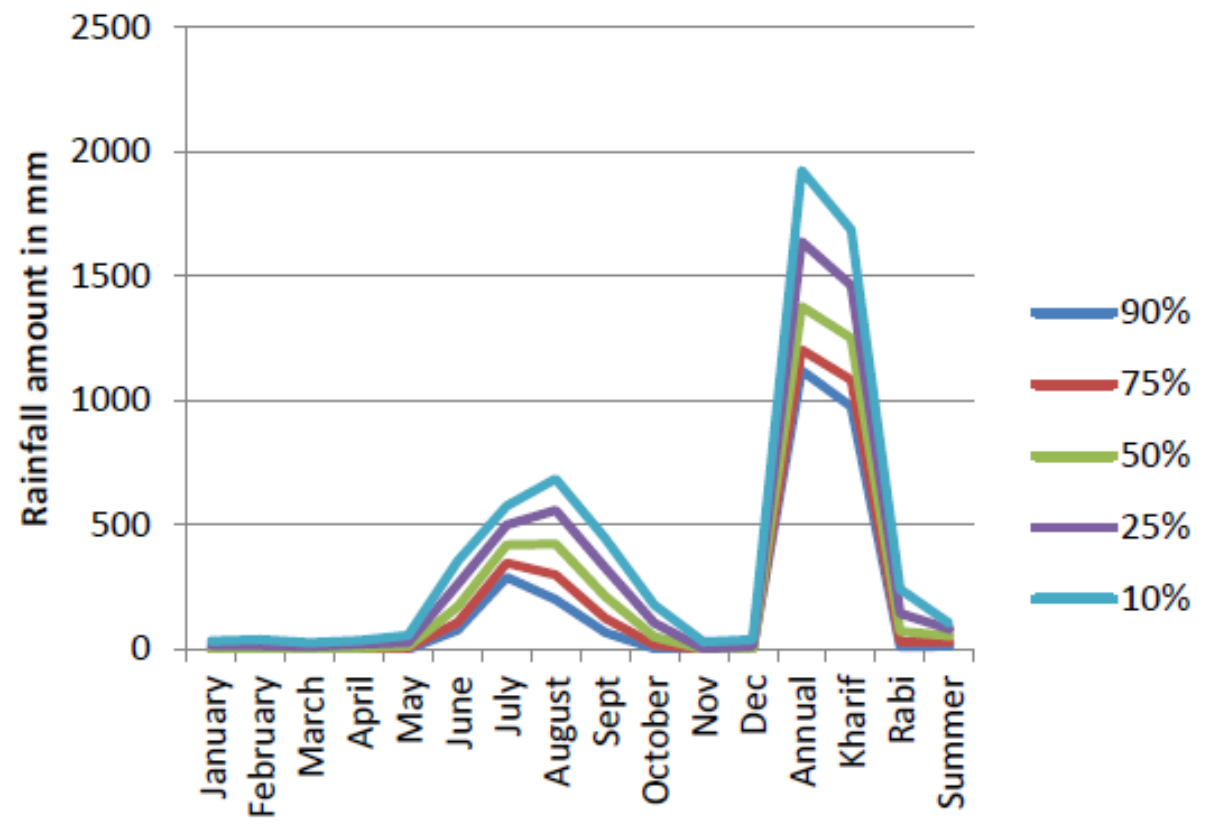

Months,Seasons and Annual

Figure I Rainfall at different probabilities of monthly, seasonal and annual at Sambalpur block. 


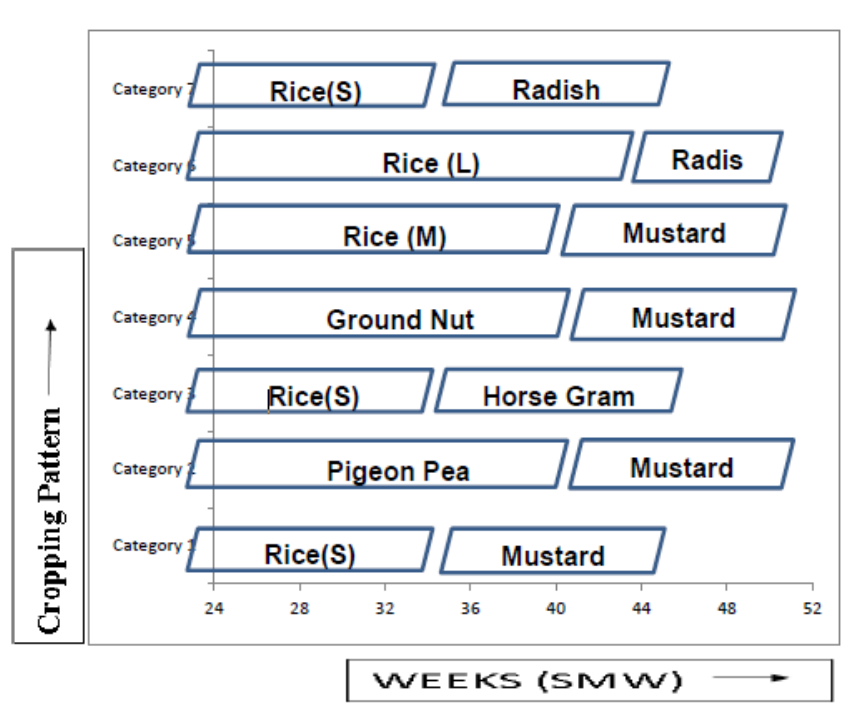

Figure 2 Different cropping patterns for Sambalpur district.

\section{Conclusion}

Forecasting of rainfall is essential for proper planning of crop production. About $70 \%$ of cultivable land of Odisha depends on rainfall for crop production. Prediction of rainfall in advance helps to accomplish the agricultural operations in time. It can be concluded that, excess runoff should be harvested for irrigating post-monsoon crops. It becomes highly necessary to provide the farmers with highyielding variety of crops and such varieties which require less water and are early-maturing in Sambalpur district of Mahanadi command area of Odisha. It is also observed that at $75 \%$ probability level the June ,July, Aug and Sept received more than $100 \mathrm{~mm}$, so farmers of these area can grow crops in upland areas suitably paddy can be grown followed by any rabi crop in rabi season like mustard or kulthi in upland areas. Annual rainfall of Sambalpur district is 1377.9 $\mathrm{mm}$ at $50 \%$ probability level. It is observed that September month gets highest amount of rainfall compared to other months. Different cropping pattern selected may be may be practiced in this district.

\section{Acknowledgments}

None.

\section{Conflicts of interest}

None.

\section{References}

1. Thom HCS. Some methods of climatological analysis. WMO Tech. Note. No. 81. 1966.

2. Kar G, Singh R, Verma HN. Alternative cropping strategies for assured and efficient crop production in upland rain fed rice areas of eastern India based on rainfall analysis. Agricultural Water Management. 2004;67(1):47-62.

3. Jat ML, Singh RV, Balyan JK, et al. Analysis of weekly rainfall for Sorghum based crop planning in Udaipur region. Indian J Dry land agric Res \& Dev. 2006;21(2):114-122.

4. Senapati SC, Sahu AP, Sharma SD. Analysis of meteorological events for crop planning in rain fed uplands. Indian J Soil Cons. 2009;37(2):85-90.

5. Subudhi CR. Probability analysis for prediction of annual maximum daily rainfall of Chakapada block of Kandhamal district of Orissa. Indian J Soil Cons. 2007;35(1):84-85.

6. Gumbel EJ. Statistical theory of droughts. Proceedings of ASCE. 1954;80(439):1-19.

7. Chow VT. Hand book of Applied Hydrology. McGraw Hill Book Co, NewYork. 1964;8-28.

8. Sachan S,Thomas T, Singh RM. Probability Analysis of Rainfall in Bearma Basin of Bundelkhand Region of Madhya Pradesh. International Journal of Agriculture, Environment and Biotechnology. 2018.

9. Harshfield DM, Kohlar MA. An empirical appraisal of the Gumbel extreme procedure. J of Geophysics Research. 1960;65(6):1737-1746.

10. Panigrahi B. Probability analysis of short duration rainfall for crop planning in coastal Orissa. Indian J Soil Cons. 1998;26(2):178-182.

11. Reddy SR. Principles of Agronomy. $1^{\text {st }}$ edition. Kalyani publication. 1999.

12. Sadhab P. Study of rainfall distributions and determination of drainage coefficient: A case study for coastal belt of Orissa. M Tech. thesis. CAET. OUAT. 2002;1-126.

13. Sharda VN, Das PK. Modeling weekly rainfall data for crop planning in a sub-humid climate of India. Agricultural Water Management. 2005;76(2):120-138.

14. Subramanya K. Engineering Hydrology. $23^{\text {rd }}$ reprint. Tata Mc-graw Hill Publishing Company Ltd. 1990.

15. Subudhi CR, Suryavanshi S, Jena N. Rainfall probability analysis for crop planning in Anugul block of Anugul district of Hirakud command area of Odisha, India. International Journal of Humanities and Social Sciences. 2019;8(3):49-54.

16. Weibull W. A statistical distribution functions of wide applicability. $J$ Appl Mech.-Tran ASME. 1951;18(3):293-297. 